\author{
Andrew Kostynyuk and Mykola Nikolenko
}

\title{
IRON MOLYBDATE CATALYST STABILIZED BY CALCIUM OXIDE FOR METHANOL TO FORM ALDEH YDE CONVERSION
}

\author{
Ukrainian State University of the Chemical Engineering, \\ 8, Gagarin Av., 49005Dnipropetrovsk, Ukraine; andry_kost@mail.ru
}

Received: July 08, 2010 / Revised: August 25, 2010 / Accepted: November 23, 2010

(C) Kostynyuk A., Nikolenko M., 2011

\begin{abstract}
Regularities of methanol oxidation by atmospheric oxygen on the catalyst $\mathrm{Fe}_{2}\left(\mathrm{MoO}_{4}\right)_{3} / \mathrm{MoO}_{3} / \mathrm{CaO}=$ $=1: 0.7: 0.3$ have been studied. It was found that the speed of the process in a model flow reactor obeys the first order equation with the observed rate constant of $1.0 \mathrm{sec}^{-1}$ and the apparent activation energy of $65 \mathrm{~kJ} / \mathrm{mol}$. It was established that the selectivity of formaldehyde in the process with once-through conversion over $45 \%$ sharply decreases. The mechanism of alcohols heterogeneous catalytic oxidation, including the stages of organic compounds interaction both with metal cations and oxygen atoms of the catalyst surface was suggested.
\end{abstract}

Keywords: iron molybdate catalysts, catalysis, methanol selective oxidation, formaldehyde, inert, calcium oxide.

\section{Introduction}

The manufacturing technologies of formaldehyde production are based on the concepts of methanol oxidation with air oxygen. The reaction proceeds on the catalyst surface, which can be made of silver or mixture of iron and molybdenum oxides. The process of using the formaldehyde metal-oxide catalyst is considered to be more advanced. Its application permits to achieve $99 \%$ methanol conversion and to get concentrated non-methanol formalin [1].

In this paper, the catalytic properties of the catalyst $\mathrm{Fe}_{2}\left(\mathrm{MoO}_{4}\right)_{3} / \mathrm{MoO}_{3} / \mathrm{CaO}=1: 0.7: 0.3$ are studied. By means of the known method of producing iron molybdate catalyst by mixing solutions of ammonium heptamolybdate and salts of iron after drying and dehydration of the sludge fine-dispersed powder is obtained. Then the granules of desired size are formed, but there is a problem with the strength of granules. In our view, the problem of compacting the catalyst can be solved by adding quicklime. The ratio of molybdenum oxide and iron molybdate is selected on the basis of reliably known data that a catalyst with a ratio of the number of atoms of $\mathrm{Mo} / \mathrm{Fe}=2.2: 1$ has the greatest catalytic activity $[2,3]$. Adding the catalyst to the inert substance is a convenient way to manage its adsorptive properties [4]. The problem is that in literature it was suggested that the high selectivity of iron molybdenum catalyst by partial oxidation of methanol may be due to low formaldehyde molecules adsorption on its surface. Therefore, an artificial decrease in the adsorption capacity of the catalyst can promote the increase of selectivity for the process of methanol partial oxidation. Microheterogeneity of a catalytic system should significantly change the value of mass and heat transfer generation on the catalyst surface, which may appreciably change a diffusion rate and the rate of chemical processes and influence the ratio of oxidation rate constants of methanol and formaldehyde molecules.

\section{Experimental}

Synthesis was carried out by mixing the required quantities of iron(III) nitrate and ammonium heptamolybdate, qualified as chemically pure, dissolved in nitric acid $(\mathrm{pH}=2)$. Solution of iron(III) nitrate was added dropby-drop to the solution of ammonium heptamolybdate, which was intensively stirred at $333 \mathrm{~K}$. The obtained suspension was evaporated; the residue was dried at $363 \mathrm{~K}$, then at $383 \mathrm{~K}$ and then subjected to calcination at $773 \mathrm{~K}$ within $48 \mathrm{~h}[2,3]$.

To study the hardness of the catalyst it was mixed with calcium oxide in the ratio from 0 to 0.5 . The samples were formed as a cube with $1.4 \mathrm{~cm}$ face. Then the catalyst was dried at the temperature of $473 \mathrm{~K}$ and calcined during $1 \mathrm{~h}$ at $773 \mathrm{~K}$.

Investigation of methanol catalytic oxidation was performed on a pilot plant with a flow reactor in a U-shaped tube with an internal diameter of $9 \mathrm{~mm}$ and a bulk catalyst volume of $7.0 \mathrm{~cm}^{3}$. The reactor was inserted in the tubular furnace, the heating being automatically regulated with accuracy of $\pm 5 \mathrm{~K}$ by thermal regulators. Thermocouples were placed inside the reactor in the middle of the catalyst layer. For obtaining the air-methanol mixture the dry air 
flow was mixed with methanol vapors in a predetermined ratio. The flows of the air and the methanol vapor were recorded by calibrated rheometers. Alcohol content in the saturated vapor was determined on the basis of published data about the temperature dependence of the partial vapor pressures of the methanol. The methanol-air mixture was conveyed to the reactor at the rate of $0.2-0.7 \mathrm{l} / \mathrm{min}$. The reaction mixture samples were selected in the absorber with water. The analysis of the gas mixture determined the amount of formaldehyde and methanol [4].

\section{Results and Discussion}

To select the optimum amount of binding component, which could provide the greatest strength of catalyst pellets and would not affect its catalytic properties, the catalyst samples with different amount of $\mathrm{CaO}$ were prepared. According to the results of the samples strength studies (Fig. 1) it was concluded that the optimum ratio of FeMo-catalyst and $\mathrm{CaO}$ is $85: 15$.

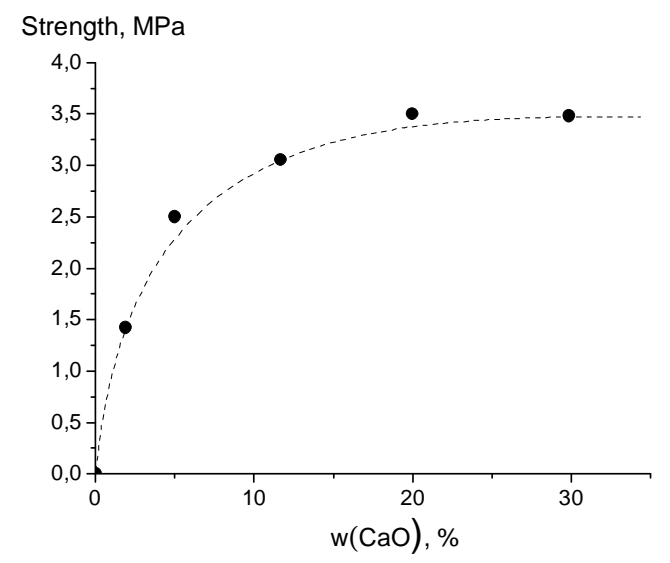

Fig. 1. Strength of FeMo-catalyst pellets as a function of the $\mathrm{CaO}$ amount

In further work the granulated catalyst was used, which was received by mixing initial powders with the necessary amount of slaked lime. The resultant mixture was dried for a week in the air, and then within $2 \mathrm{~h}$ at $383 \mathrm{~K}$ it was grinded and the fraction of particles with dimensions $0.25-1 \mathrm{~mm}$ was sifted.

Research was conducted at the same initial concentrations of methanol vapor $-1.25 \mathrm{~mol} / \mathrm{m}^{3}(3 \mathrm{vol} \%)$. Such alcohol vapor content is half as much as the concentration of air-alcohol mixture self-ignition but at the same time it is high enough for saturation of the catalyst surface with methanol molecules. To achieve steady-state processes of mass and heat transfer all the kinetic studies began no earlier than $30 \mathrm{~min}$ after determining the necessary expenses of reaction mixture or heating the reactor to the desired constant temperature. In the experiment the degree of methanol conversion varied in the range of 40
$60 \%$. To describe the kinetic data the model of ideal displacement reactor was used. According to the content of methanol in the gas stream leaving the reactor and the tentative time $(\tau)$ of the process defined as the ratio of bulk volume of the catalyst to the value of volumetric flow rate of the reaction mixture, the order of kinetic equation and the observed rate constant for the process were determined. It was found that the experimental data are well linearized in coordinates of the first-order equation $\ln C-\tau$. The observed rate constant was $1.0 \mathrm{~s}^{-1}$ (relative standard deviation $-0.2 \%)$.

For determination the stage that limits the overall rate of the process the measurements of methanol content in the gas flow at a constant value of $\tau$ but at different temperatures in the range $573-673 \mathrm{~K}$ were conducted. It was found that the obtained results are linearized in coordinates of the Arrhenius equation with apparent activation energy of $65 \mathrm{~kJ} / \mathrm{mol}$. According to research in the flow-circulating reactor the activation energy of oxidation

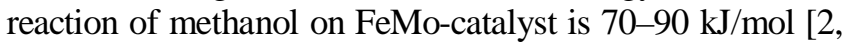
$3,5]$. It is known that at high speeds of circulation and a thin layer of the catalyst in such systems practically there is no gradients of concentration and temperature. Therefore, the experiment under such conditions allows to investigate the process in the kinetic region when the chemical interaction is the stage that limits the process and the observable rate constant coincides with the constant reaction rate. Understated value of the activation energy for the process of methanol oxidation in the integral reactor is the evidence rather not of the properties of the investigated catalyst, but that the process develops in the transition region. It is known that in the transition region the selectivity of consecutive reactions of useful intermediates rapidly decreases reaching a constant minimum value in the diffusion region. Obviously, this effect holds in our case.

Fig. 2 presents the results of changes in the concentrations of methanol and formaldehyde with the growth of conventional time $(\tau)$ of the reaction mixture in a reactor. It was found that a formaldehyde yield at $\tau>0.014$ min exponentially reduces. In our opinion, this can be explained by the transition of the process to the kinetic region with the increase of the volumetric feed rate of the reaction mixture. Unfortunately, the dispersion of experimental points on the kinetic curves $\mathrm{C}(\tau)$ doesn't allow to detect probable fracture at $\tau \sim 0.014 \mathrm{~min}$. It should be noted that we didn't succeed in describing by one kinetic equation the experimental data on the yield of formaldehyde in the approximation scheme of two successive reactions: $\mathrm{CH}_{3} \mathrm{OH} \rightarrow \mathrm{CH}_{2} \mathrm{O} \rightarrow \mathrm{CO}$ not only for the first order reactions, but even while using static or rational kinetic equations. It was found that the obtained data on formaldehyde yield is best described by two separate kinetic curves of the first order for $\tau<0.014$ and $\tau>0.014 \mathrm{~min}$. Obviously this fact indicates a qualitative 
change of the mechanism of the oxidation process, while reducing the volumetric feed rate of the reaction mixture in the reactor.

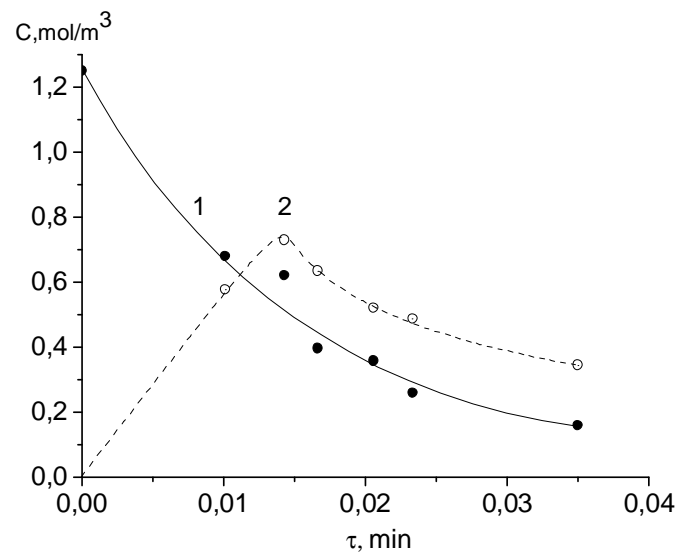

Fig. 2. Dependence of methanol (1) and formaldehyde (2) concentrations on conventional reaction time of oxidation process at $573 \mathrm{~K}$ (curve 1 based on the kinetic equation for first-order rate constant $1.0 \mathrm{~s}^{-1}$ and $C_{0}=1.25 \mathrm{~mol} / \mathrm{m}^{3}$ )

It should be noted that similar patterns of changes in selectivity with increasing degree of conversion of raw materials were studied experimentally and theoretically. For example [3] presents detailed data on the selectivity of the process of the methanol oxidation on iron molybdate catalysts at different ratio of $\mathrm{Mo} / \mathrm{Fe}$. It was established that the selectivity values of methanol oxidation to formaldehyde with the increase of the degree of its transformation at first remains almost constant and then rapidly decreases. For catalysts containing an excess of molybdenum oxide with a ratio of $\mathrm{Mo} / \mathrm{Fe}=1.4: 1$, such reducing the selectivity is observed when $\mathrm{X}>95 \%$, and for the catalyst with a ratio of $\mathrm{Mo} / \mathrm{Fe}=1: 1$ selectivity decline begins at $X \sim 45 \%$.

Fig. 3 shows a similar dependence of the oxidation process selectivity of methanol to formaldehyde on the degree of its transformation, which we built on the basis of the experimental data. According to these data, when $\mathrm{X}>$ $45 \%$ the process selectivity decreases dramatically. Having compared the curve in Fig. 4 with the data given by the authors [3] we can conclude that the catalytic properties of catalysts investigated are close to the properties of the similar catalyst with a ratio of $\mathrm{Mo} / \mathrm{Fe}=1: 1$. In our opinion, this fact can be explained by the possibility of interaction between calcium ions and molybdate ions in the bulk of the catalyst with the formation of $\mathrm{CaMoO}_{4}$. Obviously, the presence of calcium molybdate in the synthesized catalyst increases the selectivity of methanol oxidation to formaldehyde up to $100 \%$ at small transformations of methanol. Subsequent reduction of the catalyst selectivity in higher degrees of methanol conversion is caused by insufficient content of free molybdenum oxide in the catalyst. Obviously the synthesis of FeMo-catalyst with the addition of $\mathrm{CaO}$ should be performed at high molybdenum content, so that after the formation of calcium molybdates its residual concentration in the catalyst was maintained with the ratio of $\mathrm{Mo} / \mathrm{Fe}=$ $=1.5: 1$.

Nowadays in literature a number of kinetic equations which are determined by alcohol and oxygen concentrations were proposed for the oxidation reaction of methanol with the air oxygen $[5,6]$. For highly concentrated alcohol-air mixtures (up to $6.5 \%$ methanol and $19 \%$ oxygen) it was assumed that oxidation reaction is of the zero order for oxygen, and for methanol in model catalysts it is usually less than one, whereas for industrial catalysts the first order reaction is often realized.

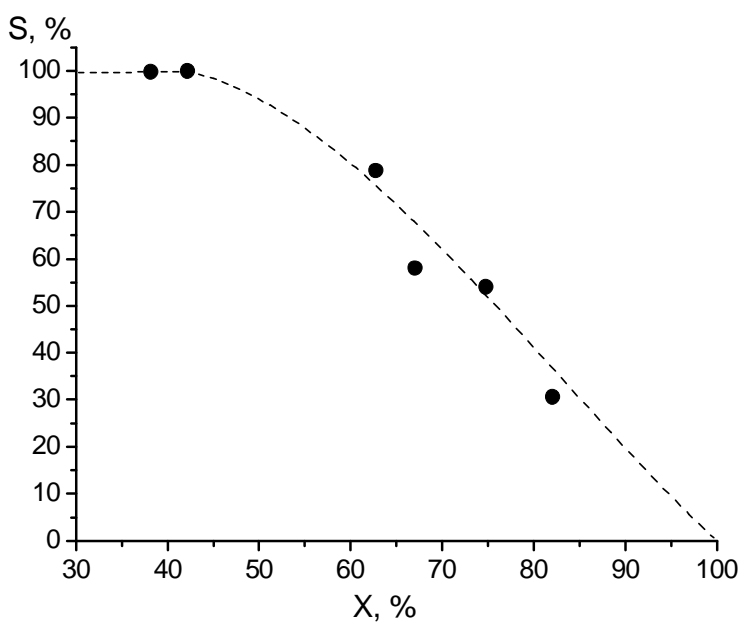

Fig.3. Comparison of selectivity to formaldehyde of the catalyst $\mathrm{Fe}_{2}\left(\mathrm{MoO}_{4}\right)_{3} / \mathrm{MoO}_{3} / \mathrm{CaO}=1: 0.7: 0.3$ at varying methanol conversions at $573 \mathrm{~K}$

Explanations of these patterns are based on the assumption of selective adsorption of the reactions on different active centers of the catalyst surface. In the literature the question on the dominant character of the above adsorption interaction still remains controversial. Obviously, the structure of the formed adsorptive compounds should largely determine the structure of the transition state "methanol-active form of the oxygen". Typically, the molecules adsorption of alcohol (as well as of formaldehyde) on the oxide surface is considered as the result of the interaction between the oxygen atom of organic molecules and the surface metal cation.

It is obvious that in forming the surface compound $\equiv \mathrm{Me}-\mathrm{O}(\mathrm{H}) \mathrm{CH}_{3}$ the overall rate of the process can be controlled by the concentration of surface metal cations (Lewis acid centers) and therefore correlation between the rate of oxidation and the energy of lattice oxygen becomes possible. Such dependence is satisfied, for example, for oxides of cobalt, manganese, nickel and chromium, which are characterized by low energy of oxygen bond [7]. Alcohol molecule chemisorbed via oxygen is oxidized to 
formaldehyde, the latter remaining on the surface in the adsorbed state. A part of the adsorbed formaldehyde is desorbed, and the other part undergoes further oxidation to formic acid. In our opinion, this route of reaction leading to the formation of adsorbed formaldehyde causes a high rate of subsequent oxidation stage and appears to be the main reason for the low selectivity of these oxides in the oxidation of the intermediate product.

In case of oxides and metal molybdates with high bond energy of oxygen one can assume that surface concentration of metal ions which have lost oxygen and become available for adsorption of oxygen-containing organic molecules is very small. Large excess of oxygen in the reaction mixture is another factor that promotes the decrease in the concentration of free metal cations. In our opinion, among the possible mechanisms of polar organic molecules adsorption under such conditions the form of adsorption with the participation of surface oxygen may prevail. Bonding with the lattice oxygen being possible only for positively charged atoms of adsorbed molecules, i.e. atoms of hydrogen and (or) carbon, the molecule must be oriented on the surface with its carbon radical. According to current knowledge of organic chemistry [8], the most favorable way for the process of alcohol molecule oxidation is considered to be the attack by nucleophilic reagent such as active oxygen atom of the oxide surface. This attack is directed to the $\mathrm{C}-\mathrm{H}$ bond, which in contrast to alkane molecules is more active due to a polarizing effect of OH-groups of alcohol molecules. The result of this interaction is oxygen atom introduction between the atoms of $\mathrm{C}-\mathrm{H}$ bond.

Possibility for transition state formaldehyde molecule with chemisorbed or lattice oxygen to be formed on the surface of molybdenum oxide catalyst was studied by the authors [9] using the method of quantum chemical modelling. It was shown that under nucleophilic attack of the carbon atom there exist two possible directions for the change of activated complex: the first is the split of $\mathrm{C}-\mathrm{H}$ bond with the formation of $\mathrm{CO}$ and chemisorbed molecule of $\mathrm{H}_{2} \mathrm{O}$ the second includes a weakening one of $\mathrm{C}-\mathrm{H}$ bonds with the introduction of oxygen atom and the formation of formic acid.

Thus, the scheme of methanol oxidation on oxide iron molybdate catalyst can be represented as follows:

$$
\mathrm{CH}_{3} \mathrm{OH}_{\text {g.f. }} \underset{\mathrm{k}_{2}}{\stackrel{\mathrm{k}_{1}}{\longrightarrow}} \mathrm{CH}_{3} \mathrm{OH}_{\text {ads. }} \stackrel{\mathrm{k}_{3}}{\longrightarrow} \mathrm{CH}_{2} \mathrm{O}_{\text {ads. }} \rightarrow \mathrm{\rightarrow CO}
$$

where $k_{1}$ and $k_{2}$ - rate constants of adsorption and desorption; $k_{3}$ - the rate constant for chemical transformation; g.f. - gas phase; ads. - adsorbed state.

Kinetic equations for the first part of the considered scheme can be written in the following form:

$$
\begin{gathered}
r_{\text {ads. }}=-k_{l} C_{\mathrm{CH} 3 \mathrm{OH}, \text { g.f. }}\left(1-\theta_{\mathrm{CH} 3 \mathrm{OH}}\right)+k_{2} \theta_{\mathrm{CH} 3 \mathrm{OH}} \\
r_{\text {ch.r. }}=-k_{3} \theta_{\mathrm{CH} 3 \mathrm{OH}}^{*}
\end{gathered}
$$

where $\theta_{\mathrm{CH} \text { OH }}^{*}=\alpha \theta_{\mathrm{CH} 3 \mathrm{OH}}, \alpha-\mathrm{a}$ fraction of alcohol molecules, adsorbed with the participation of surface oxide oxygen, of the total number of adsorbed molecules of methanol.

Since in the steady state $r_{a d s .}=r_{\text {ch.r. }}$, comparing the equations we can express the value $\theta_{\mathrm{CH} 3 \mathrm{OH}}$ by the rate constants of elementary stages and the concentration of methanol in the gas phase. After substituting this expression into the formula for the rate of chemical reaction we obtain the kinetic equation

$$
r_{\text {ch.r. }}=-\frac{k_{3} C_{\mathrm{CH}_{3} \mathrm{OH}, \text { g.f. }}}{\frac{k_{3}}{k_{1}}+\frac{k_{2}}{\alpha k_{1}}+\frac{1}{\alpha} C_{\mathrm{CH}_{3} \mathrm{OH}, \text { g.f. }}}
$$

according to which the order of the oxidation of methanol with the corresponding values of the constants may be less than the unit. Thus, this results in a kinetic equation with a reduced order of methanol reaction.

It should be noted that these equations for the rates of methanol oxidation and formaldehyde on iron-molybdenum oxide catalyst were first proposed by the authors $[5,6]$. For oxidation of methanol on an industrial catalyst, the authors [5] simplify the equation, substituting methanol concentration in the denominator for its original value, which increases the reaction order up to one. In the proposed kinetic equation the transition to the first order equation is possible at a sufficiently high concentration of "rightly" adsorbed alcohol molecules. It is obvious that with decreasing concentrations of methanol in the reaction medium, the methanol content on the catalyst surface will be reduced. Thus, the relationship between different forms of adsorption will change as well. Apparently, this fact can explain the observed decrease in the yield of formaldehyde and selectivity of the process with the increasing degree of methanol conversion (see Figs. 2 and 3).

\section{Conclusions}

As a result of the studies it was found that the greatest strength is reached at a ratio of the catalyst and the quicklime $85: 15$. In the stationary isothermal mode the air oxidation rate of methanol on the catalyst with the composition of $\mathrm{Fe}_{2}\left(\mathrm{MoO}_{4}\right)_{3} / \mathrm{MoO}_{3} / \mathrm{CaO}=1: 0.7: 0.3$ in the pilot flow reactor obeys the first-order equation with the imaginary activation energy of $65 \mathrm{~kJ} / \mathrm{mol}$. It was established that when methanol-air mixture remains in the reactor for more than $0.014 \mathrm{~min}$ the product yield exponentially decreases. We failed to define the kinetic equation for this process in successive approximation scheme $\mathrm{CH}_{3} \mathrm{OH} \rightarrow \mathrm{CH}_{2} \mathrm{O} \rightarrow \mathrm{CO}$ using even static or rational kinetic equations. Obviously, this fact indicates a qualitative change of the mechanism of oxidation process, while reducing the volume velocity of the reaction mixture supply in the reactor. 
It was found that after adding $\mathrm{CaO}$ to the iron molybdate catalyst with a ratio of $\mathrm{Mo} / \mathrm{Fe}=1.5: 1$ its activity decreases to the level typical for catalysts with a ratio of $\mathrm{Mo} / \mathrm{Fe}=1: 1$. It was concluded that in the volume of the catalyst during its granulation $\mathrm{CaMoO}_{4}$ is formed, which reduces the proportion of molybdenum oxide(III) excess. Therefore, using calcium oxide synthesis of FeMocatalyst should be conducted at a higher content of molybdenum oxide.

It was suggested to consider heterogeneous-catalytic oxidation of methanol and formaldehyde with due account of two forms for their molecules adsorption: when bonding oxygen atoms the Lewis acid sites or the interaction of carbon and hydrogen atoms of the $\mathrm{C}-\mathrm{H}$ bonds with the Lewis basic centers of the catalyst. Obviously, the ratio between the amounts of these forms on the surface of the catalyst is determined not only by its properties (for example, by the binding energy of the lattice oxygen or $\mathrm{pH}$ value), but also by degree of surface coverage by oxidized compounds. Apparently, the change in the proportion of different forms of adsorbed molecules of methanol and formaldehyde causes the change in the mechanism of the process, which is observed at the residence of reaction mixture in the reactor for more than $0.014 \mathrm{~min}$.

\section{References}

[1] Ogorodnikov S.: Formal'degid. Himiya, Leningrad 1984. [2] Bowker M., Holroyd R., House M., et al.: Topics in Catalysis, 2008, 48, 158.
[3] House M., Carley A., Echeverria-Valda R. and Bowker M.: J. Phys. Chem., 2008, 112, 4333.

[4] Nikolenko N. and Kostynyuk A.: Voprosy Khimii i Khim. Techn., 2009, 4, 220.

[5] Bibin V. and Popov B.: Kinetika i Kataliz, 1969, 10, 1326.

[6] Evmenenko N. and Gorohovatskij Ya.: ibid, 1299.

[7] Golodec G.: Teor. i Experem. Khimiya, 1982, 1, 37.

[8] Berezin B. and Berezin D.: Kurs Sovremennoj Organicheskoj Khimii. Vysshaya shkola, Moskwa 2001.

[9] Gagarin S., Gorshkov A. and Margolis L.: Kinetika i Kataliz, 1972, 13, 136.

\section{ЗАЛІЗО-МОЛІБДЕНОВИЙ КАТАЛІЗАТОР СТАБІЛІЗОВАНИЙ ОКСИДОМ КАЛЬЦЮЮ ДЛЯ КОНВЕРСІЇ МЕТАНОЛУ В ФОРМАЛЬДЕГІД}

Анотація. Вивчено закономірності окиснення метанолу киснем повітря на каталізаторі складу $\mathrm{Fe}_{2}\left(\mathrm{MoO}_{4}\right)_{3} / \mathrm{MoO} \mathrm{O}_{3} / \mathrm{CaO}=$ $1: 0,7: 0,3$. Знайдено, щзо швидкість прочесу в модельному проточному реакторі підпорядковується рівнянню першого порядку зі спостережуваною константою швидкості $1,0 c^{-1} i$ уявною енергією активації 65 кДю/моль. Встановлено, щзо селективність процесу по формальдегіду при ступені перетворення метанолу більше 45 \% різко зменшується. Запропоновано механізм гетерогенно-каталітичного окиснення спиртів, який включає стадї взаємодії органічних сполук як з катіонами металу, так і атомами кисню поверхні каталізатору.

Ключові слова: залізо-молібденовий каталізатор, каталіз, селективне окиснення метанолу, формальдегід, інерт, оксид кальијю. 